\title{
12. Problems of captured collaboration: from political to politicized metagovernance
}

\author{
Anka Kekez and Andrija Henjak
}

\section{INTRODUCTION}

Collaboration between public, private and civic actors has in recent years been at the center of efforts to reform the public sector and devolve its policy-making and implementation capacity. As a result of these efforts, the provision of many social, health, education, and other services in modern societies is based on collaborative mixes combining elements of state-centered, market-centered and network-centered modes of governance. It is considered that the development of such mixes enables governments to mobilize a wider range of actors and resources in the production of high-quality public services. Within the Network and Civil Society-State Governance, for example, Co-production, Co-management and Consultations arguably not only enable a better understanding of citizens' needs and challenges related to designing programs to meet those needs, but also create conditions conducive for effective delivery of services. On the other hand, collaboratively designed Contracting in Market Governance, Commissioning in Corporatist Governance and Certification in Private Governance, can complement efforts by the public sector to enhance efficiency, flexibility and access to innovation, technology and expertise available within the scope of private sector or civil society.

However, the theoretical potential of collaborative implementation mixes can hardly be matched in practice if they are deployed by actors lacking certain critical policy-making and governing capacities. As it is put forward in the introductory chapter to this volume, successful governance of each of the collaborative arrangements mentioned above requires a certain combination of analytical competences to define problems and formulate solutions; of managerial competences to effectively employ state resources in order to achieve policy objectives; and of political competences to ensure support for effective policy design and implementation (see also Howlett and Ramesh 2016). 
Among the above three types, political capacities are particularly critical for the success of collaborative arrangements. More specifically, as highlighted in the introductory chapter, political competences crucial for collaborative service delivery are the willingness and ability of political leaders to govern collaboration by shifting focus away from affecting the substance of government service delivery toward facilitating interaction between government and societal actors.

In collaborative governing endeavors, executive politicians are required to relinquish the idea of dominating and controlling the governance arena in which collaboration takes place and are instead invited to engage in the exercise of metagovernance (Agranoff and McGuire 2004; Kickert, Klijn, and Koppenjan 1997; Koppenjan and Klijn 2004). Acting as political metagovernors, instead of commanding actors when designing actual solutions, they shape collaborative processes and outcomes by inviting actors to engage in interactive design and the delivery of public services, determining process rules and engaging in the soft forms of steering (Agranoff and McGuire 2004; Sørensen and Torfing 2016a, 2016b). Nevertheless, in practice, the prospects for successful fulfilment of metagoverning tasks can be challenged from two perspectives. First, as the studies of reform processes have shown, it is not very likely that politicians would give up authority over policy content that easily and thus willingly limit themselves to the role of process moderators (Pollitt and Bouckaert 2011). Second, even if that happens, politicians can act more as 'spoilsports' then as 'playmakers' (Klijn and Koppenjan 2000a).

If incentivised to do the latter, they may use the role of guarantors of compromise deals between multiple stakeholders within the framework of collaboration in order to advance their own interests and objectives. In a context characterized by the prevalence of consensual governing conventions or the presence of pressures from the public, collaborative arrangements can be metagoverned by means of soft institutional forms so as to represent an enhancement instead of a threat to democracy (Ansell, Sørensen, and Torfing 2017; Sørensen 2013). Nonetheless, as this chapter argues, if performed by elected officials incentivized to engage in party patronage or politicized allocation of public goods and jobs, the metagovernance role can also be adjusted to serve particularistic spoil-seeking interests.

Where the political executive is inclined to engage in spoil-seeking activities, as one of the authors' recent study of the reform of social services in Croatia demonstrated (Kekez 2018a), the metagoverning exercise might provide political actors with opportunities for manipulating the design of rules governing this process in order to insert political interests into the selection of actors that will act as service providers or users. In other words, collaboration-inspired reform of public services and reliance on soft steering can enable rent-seeking politicians to create opportunities and resources for advancing political objec- 
tives, and even to use these opportunities at the expense of objectives set by public policy. Still, such capture or politicization of public services is more likely to take place in a political system where political actors are not held accountable for the quality and quantity of services delivered, but are instead evaluated more on the basis of how well they represent particular political, religious or ethnic identities.

However, it also has to be noted that the politicization of public services might have positive effects. These include a wider inclusion of citizens in targeted communities or the recruitment of underdeveloped, but politically important local communities into service provision networks. On the other hand, politicization tends to result in an unequal availability of a service, as well as in the perception that the allocation of resources to selected providers or beneficiaries is being used as a direct material incentive for inducing the desired electoral behavior. This perception need not apply to all providers and users of the service, but it can nevertheless seriously harm its sustainability when the party pursuing politicization of public services loses power. If the provision of services is heavily politicized, the change of a governing party can result in the deliberate gutting of policy directed at limiting resources available to actors affiliated with the previous governing party or at freeing resources for rent-seeking activities of the new governing party (Kekez 2019). Furthermore, if a policy or a service is seen as politicized, periodic changes and alterations dependent on the political cycle resulting from it are likely to prevent the development of capacities for policy implementation as changes in policy direction and personnel involved in implementation will create discontinuity which will prevent institutional learning.

The question which arises is what enables political actors to use a collaboration-inspired reform of public services to capture the implementation process and introduce patronage practices. Or to put it more precisely, when provided with a favorable opportunity structure, which pathways do political actors use to introduce partisan patronage without suffering electoral punishment or the loss of political legitimacy for misusing the reform process for partisan agenda? This chapter aims to move beyond simply describing a pattern of regular association between reform conditions and results in specific services to open up the black box of causality to understand exactly how, in specific conditions, (re)design of collaborative arrangements run by patronage-driven politicians can lead to the capture of service delivery in line with those patronage practices.

To this end we first discuss what incentivizes political actors to use the metagovernance process to politicize public service reform. Next, we discuss how political actors can use the metagovernance process to capture reform for political ends. Going further, we also discuss conditions enabling political actors to do this and constraints preventing them from doing it. Finally, we 
illustrate the whole process by presenting a case of the reform of elderly home care in Croatia as an example of a service reform where the politicization of metagovernance took place.

\section{INCENTIVES FOR POLITICAL CAPTURE OF SERVICE DELIVERY}

The incentive structure of political actors in competitive democracies is shaped within the strategic nexus where political actors need to reconcile electoral, office and policy-related objectives (Strøm 1990). This strategic nexus is substantially more complex than the one faced by administrative leaders, since political leaders need to balance between a wider set of often conflicting objectives. This forces politicians to make strategic choices which are often inconsistent with purely policy-related priorities and to make trade-offs between objectives (see Strøm and Müller 1999). In other words, if faced with a favorable opportunity structure with sufficiently strong pull factors, political leaders would likely use changes in metagoverning structures to fulfil other than policy-related objectives.

Politicians' choices between strategic objectives are shaped by the nature of party-voter linkages and democratic accountability mechanisms (Kitschelt and Wilkinson 2007). Party-voter linkages can be programmatic when voters support or oppose political actors for policies they deliver; clientelistic when voters and politicians join into a more or less direct exchange of selective goods for votes; and charismatic or symbolic when voters support political actors because of their charisma or because of what they symbolize ${ }^{1}$ (Kitschelt 2000). Accountability mechanisms, or channels through which voters hold political actors responsible for their actions are closely linked to party-voter linkages. In a programmatic competition, voters hold political actors accountable for policies they enact and outcomes they deliver. With charismatic linkages, political actors do hold a significant degree of freedom of action as long as their actions do not undermine the foundation of charismatic attachment or symbols sustaining this attachment. Where clientelistic linkages dominate, accountability is replaced by an exchange between voters and political actors. Votes are exchanged for selective goods tailored for particular groups of supporters while political actors monitor the exchange and exclude the non-compliant voters from participation in the exchange (Kitschelt and Wilkinson 2007).

Among these three combinations of party-voter linkages and accountability mechanisms, programmatic competition depends the most on the success of policy design and delivery and is therefore the least suitable for political capture of public services. In clientelistic competition, on the other hand, political actors use public policies for politicized tailoring of selective benefits 
targeting citizens whose voting behavior can be monitored (Kitschelt 2000; Kitschelt and Wilkinson 2007). Pure clientelistic linkages based on direct exchange of selective goods and large-scale monitoring, however, are rare and difficult to organize in developed democracies. This is because most public policies in modern democratic societies, including those directed at clearly defined groups, are delivered through rule-governed administrative procedures which do not allow politicians discretion in providing or depriving individual users of goods, which is a necessary condition for clientelistic exchange. In modern democracies, policy decision not grounded in rules can be challenged in courts. Discretionary actions violating the principles of law delegitimize policy outcomes and enable media, interest groups, courts and opposition parties to hold the government accountable.

Still, public policies are not significant just because of goods and services they deliver. Public policies can also be used as symbols indicating to the electorate that parties care about their interests and values (Dunleavy 1991). Wider electoral support can therefore be built by forming an electoral coalition using symbolically potent policies to attract voters (see Huber and Stephens 2001; Manow and van Kersbergen 2009). While such policies can constitute a significant part of public spending and cover a substantial segment of the population, their political relevance lies in their strengths as symbols for mobilizing voters. Similarly, parties can use partial or limited policy measures if these carry large symbolic meaning. ${ }^{2}$ Still, the success of these policies, even if symbolically potent, is dependent on the ability of a political party to deliver a relevant political message to its voters (Brooks and Manza 2007). This requires a party organization capable of formulating and disseminating political messages and getting voters to the polls.

Constrained by rules and institutions limiting the use of public policies for clientelistic exchange with voters, parties using policies as symbols are therefore incentivized to engage in political patronage as a specific kind of clientelistic practice that serves the purpose of party organization building. In party patronage, politicized allocation of public jobs and of other valuable public resources is directed at a relatively small number of party members or activists which can be mobilized by the party organization for building electoral infrastructure, transmitting electoral messages and mobilizing voters or organizing and participating in protests and other political activities (Kopecký and Spirova 2011; Stokes et al. 2013). Furthermore, politicized allocation of public jobs and procurements or privileged access to public goods and services, can be used to build quasi-political organizations which can be used for organizing political protests and turning out voters previously mobilized by public policies carrying important symbolic significance.

As patronage primarily relies on exploitation of public employment and contracts, the best opportunities for collecting these forms of rents are available by 
means of political interventions in hiring service providers; biased allocations of public funding; and other similar forms of politicization of public service delivery (Chandra 2007; Kekez 2018a; Ruth 2019). Moreover, proven to be an adaptive strategy of electoral mobilization, patronage may not only produce political resistance to public service reform, but even incentivize politicians to misuse reform ideas and tools for their spoil-seeking needs (Peters 2010; Grindle 2012; Kekez 2019).

Consequently, some of the core ideas and tools behind collaboration-inspired public service reforms are highly attractive for capture to spoil-seeking politicians. Among others, these include managerial reliance on trust and other soft steering tools which induce intrinsic cooperation between actors engaged in governance processes, but can also lead toward the invalidation of state oversight functions (Bell and Hindmoor 2009; Klijn 2010). In addition, the introduction of complex implementation networks and partnerships enables the generation of informed and flexible policy solutions, but it also converts the assignment of responsibilities into an extremely difficult task, to say the least (Bovens 1998; Papadopoulos 2003). With such underlying properties, changes promoted by collaboration-inspired reform in themselves hold the potential to offer politicians a space to undermine regulatory and other institutional constraints (Papadopoulos 2003; Peters and Pierre 2004). If that space is to be governed by politicians incentivized to engage in spoil-seeking activities, as this chapter argues, the reform may be used for the political capture of collaborative public service delivery.

\section{PATHWAY TO CAPTURE: POLITICIZATION OF THE METAGOVERNANCE PROCESS}

In explaining how political capture of collaboration can be possible, we need to address the role of executive politicians in the process through which collaboration-inspired reformist ideas are turned into a service delivery practice. This process is conceived here through the lenses of governance theory. Decisions of elites regarding changes in structure and processes in the public sector are, as Table 12.1 shows, subsumed under the concept of metagovernance which "in its most basic and general (but also most eclectic) sense, denotes the governance of governance" (Jessop 2011: 106). In the literature, metagovernance is primarily conceived as an administrative exercise directed at turning interactive governance arenas into smoothly functioning mechanisms for consensus-based co-governance. However, metagovernance is also the concept which can help us understand how political leadership can be practiced in the world of collaborative governance (Sørensen and Torfing 2016a, 2016b). 
Table 12.1 Political metagovernance: activities on different action levels and scales

\begin{tabular}{|c|c|c|c|}
\hline \multirow[t]{2}{*}{ Action scale } & \multicolumn{2}{|c|}{ Action level of political metagovernance } & \multirow{2}{*}{$\begin{array}{l}\text { Operational } \\
\text { governance }\end{array}$} \\
\hline & Constitutive governance & Directional governance & \\
\hline System & $\begin{array}{l}\text { Initiating institutional (re)design } \\
\text { and creating the governance arena }\end{array}$ & $\begin{array}{l}\text { Defining general rules for } \\
\text { interactive policy-making }\end{array}$ & \multirow{3}{*}{$\begin{array}{l}\text { Collaborative } \\
\text { public service } \\
\text { delivery }\end{array}$} \\
\hline Organization & $\begin{array}{l}\text { Devolving mandate and reforming } \\
\text { the (inter)organizational setting }\end{array}$ & $\begin{array}{l}\text { Participating in negotiated } \\
\text { policy (re)design }\end{array}$ & \\
\hline Individual & $\begin{array}{l}\text { Fostering internalization of core } \\
\text { norms and values }\end{array}$ & $\begin{array}{l}\text { Ensuring acceptance and } \\
\text { interactive rule application }\end{array}$ & \\
\hline
\end{tabular}

Source: Elaborated by authors based on Hill and Hupe (2014), Kekez (2018b), Kooiman (2003), Papadopoulos (2016), Sørensen and Torfing (2016a).

The basic conceptualization of metagovernance relies on the distinction among three levels of governance, within which metagovernance refers to the second and third level (Kooiman 2003). The exercise of the third level governance, which is also referred to as the constitutive governance, includes fundamental decisions about the setups in which policy formation and implementation takes place. These decisions are meant to affect decision-making about policy content as well about organizational arrangements for its delivery (Hill and Hupe 2014; Kekez 2018b; Ostrom 2007). When applied to the collaboration-inspired reform process, the political exercise of constitutive governance implies making decisions about the initiation of reform and constitution of the governance arena that will reflect the vision of a cross-boundary, interactive and adaptive policy formation and delivery (Ansell, Sørensen, and Torfing 2017; Sørensen and Torfing 2016a). These decisions are, at the level of organization, operationalized through devolution of mandate to local communities and societal actors. At the level of individuals, this vision is communicated, and decisions substantiated though face-to-face interaction with public employees, citizens and other stakeholders (Kekez 2018b; Papadopoulos 2016; Sørensen and Torfing 2016a).

Within the normative and material structures created by constitutive governance, the aim of directional or second-order governance is to provide a framework and foster interactive formulation of policy content that will enable mobilization and empowerment of local communities and users (Hill and Hupe 2014; Sørensen and Torfing 2016a). The metagoverning task at this level includes not only the definition of fiscal, legal and discursive conditions that will frame the joint striving toward policy outcomes, but also hands-on efforts through which metagovernors engage in reflexive (re)design of policy and management tools promoted by an adopted mode of collaboration (Jessop 2011; Kekez 2018b; Kooiman 2003). The actual process of collaborative 
service delivery then in turn occurs at the level of operational governance shaped by the structure and the content designed at the two higher levels of governance (Hill and Hupe 2014; Kekez 2018b).

The core role political leaders are fulfilling when they perform all these activities is the role of democratic credentials guarantors for collaborative policy design and delivery. Whether politicians will confine themselves to the given role and to what extent, all of this may be explained when looking at their choice of electoral, office and policy-related objectives. In the exercise of constitutive governance, as this chapter argues, program-oriented politicians motivated by collaboration-inspired policy objectives are not only committed to sharing authority with networks and partnerships, but are also concerned about ensuring integrity and representativeness of the resulting governance arrangements. The fulfilment of the first of these two democratic principles implies that the government has devolved the explicit mandate and has committed administrative resources to authorized decision-makers (Fung and Wright 2003; Kekez 2018b; Sørensen and Torfing 2016a). The adoption of the second principle can be considered accomplished if the new governance arena is constituted and functioning in a way that reflects the diversity of stakeholder interests.

Even though the effectiveness of collaborative forms of service delivery relies on the usage of soft-management tools, the overly flexible constitution of the governance arena and its mandate may challenge the policy-making capacity of authorized actors (Papadopoulos 2016). Moreover, lack of appropriate procedures for selecting representatives of stakeholder interests and for balancing out asymmetries of power between them may lead to a domination of the policy-making process by unrepresentative local elites (Hysing and Lundberg 2015; Irvin and Stansbury 2004; Papadopoulos 2016). In order to ensure democratic safeguards against such scenarios, program-driven political leaders are inclined to engage in designing the process in which collaborative policy-making will take place. In this context, the key task is to frame fundamental conditions and procedures that will not only guide authorization and its potential withdrawal, but will also determine the eligibility of actors implementing the policy and benefiting from it (Bell and Hindmoor 2009; Hill and Hupe 2014; Kekez 2018b; Ostrom 2007; Papadopoulos 2016).

Those political leaders inspired not only by ideas of collaboration but also guided by motives of political patronage, on the other hand, have incentive to engage in a (re)design of collaborative arrangements for service delivery not only to allocate policy functions to local communities and societal actors, but also to do it in a way that enables politicized distribution of public goods and jobs. Politicized exercise of constitutive governance may therefore imply both the introduction of flexible settings for policy-making, as well as the institutionalization of a large degree of political discretion. This discretion can 
be further developed within the two-sided organizational and interpersonal setting in which the selection of actors authorized to act as designers and implementers of a policy is done through parallel formal and informal procedures combining legally prescribed and partisan criteria (Kekez 2018b).

In the exercise of directional metagovernance, the opportunities to use public resources for advancing political objectives can be created by distorting the principle of accountability, which is done though constitution of dysfunctional accountability mechanisms. When accountability procedures are functional, they are defining benchmarks for collaborative policy formation, while simultaneously ensuring the scrutiny of elected bodies and affected constituencies over the consequent implementation process and its results. This implies that in the exercise of directional governance, program-oriented politicians will be incentivised to set up functional rules for monitoring the arena's operative conduct and verification of its outputs. This is so, even if executive politicians are expected to steer collaborative implementation by leaving space for discretion of participants in governance arena (Jessop 2002; Koppenjan and Klijn 2004; Papadopoulos 2016).

Patronage-oriented politicians, on the contrary, will be incentivised to set up monitoring procedures where political actors retain control of the process and information about it and can limit participation and access to information of other actors. This would enable the dilution of monitoring functions and allow for a mismatch between rules-in-use and rules-in-form, where formally adopted fiscal, legal and discursive conditions of street-level work are not enacted in practice. In the actual delivery of such services, a mismatch could disturb job placement and career management systems very severely, so much so that these become distorted by excessive use of partisan and ascriptive criteria in recruiting and promoting public servants. In this way, when led by patronage-driven politicians, the metagovernance process could be misused to turn collaborative services provision into opportunities to use public resources for advancing particularistic political objectives (Kekez 2018b).

\section{CONDITIONS FOR CAPTURE}

Pervasive practices of political patronage cannot develop in just any political system, and even in a system where the party penetration of the public sector is widespread, it is likely that patronage would have a distortive impact on the collaboration-inspired metagovernance only in a specific set of circumstances where several necessary and sufficient conditions need to be met. Political cleavages formed around economic interests or programmatic competition based on redistributive issues, as well as on programmatic party voter linkages, all serve as constraints on political actors in using political patronage as they facilitate accountability based on performance evaluation. In countries where 
voters evaluate political actors based on their performance in government and not on how well they represent political symbols and identities, political actors have a significantly reduced space for using metagoverning roles in order to develop political patronage. This is because their electoral success is more in correlation with their performance in government than with their ability to build partisan networks which can be used for electoral mobilization of select social groups (see Tóka and Henjak 2007).

The necessary condition for the politicization of metagovernance processes and for the consequent capture of collaborative service delivery is political competition based on symbols and identities rather than on performance evaluation. This type of political competition has its foundation in the existence of dominant political divisions usually grounded in religion, ethnicity, historical conflicts or similar factors shaping political identities (see Kitschelt et al. 1999; Tworzecki 2003). Where political identities are strong and political competition is seen as a zero-sum game, voters are likely to support a party representing their political identity irrespective of how well this party performs in government (see Adams, Merrill and Grofman 2005). Also, where politics is seen as a zero-sum game, voters will value their preferred party staying in power and will support a party irrespective of how efficient and well-behaved it is in government. Conversely, voters will abandon a party only when it becomes disfunctionally inefficient or corrupt and when it fails in its principal objective of representing their political identity. Under these conditions political parties enjoy more freedom of action in instrumentalizing service delivery for political patronage, compared to political systems where parties are evaluated based on their performance in government and efficiency in delivering public policies.

In addition to political competition based on symbols and identity rather than on performance evaluation, politicization of metagovernance processes and outcomes depends on the characteristics of other actors involved in the delivery of public services, most notably providers and groups representing users. On the providers' side, actors whose activities are well institutionalized within autonomous organizations, with well formulated professional standards and rules, are well-placed to resist development of political patronage (Meyer-Sahling 2006; Peters 2010). Where rules and professional standards are well developed and where a high level of expertise is required in service delivery, actors involved in the provision of public services are benefiting from a high level of informational asymmetries that protect them from political infringement. On the other hand, where a service is delivered through weekly institutionalized structures with loosely defined rules and standards, the scope for political infringement is larger (Kekez 2018a; Meyer-Sahling 2006).

Also, where organizations representing users are well-organized, aware of their interests and knowledgeable about how policy affects them, and where 
they are organized into or represented by powerful advocacy groups, politicians will have less opportunities to use public policy for particularistic political aims (Schneider and Ingram 1997). On the other hand, where users are not well organized and where advocacy groups are weak, politicians will have more freedom in using public services to develop political patronage as users will likely be less aware that this is happening and thus less able to prevent it. Therefore, in the reform of weakly institutionalized services with weakly represented beneficiaries, patronage-driven politicians would be able to dilute collaboration-inspired principles and tools and merge them with patronage practices (Kekez 2018a).

\section{FROM POLITICAL TO POLITICIZED METAGOVERNANCE: THE CASE OF CROATIAN ELDERLY CARE REFORM}

In order to describe how collaboration-inspired reform might be used for political capture of public service delivery, in what follows the chapter presents the case of the reform of home care services for the elderly in Croatia. ${ }^{3}$ The case is used as an illustrative example of a metagovernance process that took place in a policy-making context with ineffective mechanisms of democratic accountability and a widespread penetration of party patronage into the public sector, both considered as powerful incentives for the politicization of public service delivery.

Since the country's independence, party-voter accountability channels in Croatia have been blurred by strong cleavages based on symbolic issues revolving around the definition of statehood, interpretations of history and the role of religion and tradition in contemporary Croatian society. At the same time, economic and distributive issues were always relatively unimportant and never became the main subject of political contestation (Henjak, Zakošek and Čular 2013; Šiber 2001). This is not to say that economic and distributive issues were not electorally relevant. Poor economic performance and the perception of incompetence and corruption were all electorally relevant, but only as drivers of mobilization or demobilization of support for government and opposition parties (Henjak 2008). In such a setting, parties were not held accountable for policy outcomes they delivered, but rather for how well they represented the expressive preferences of their voters. Even when parties had bad records of policy delivery or a record of using a policy for their own ends, the likelihood of electoral punishment was increased only when a persistent stream of scandals and negative outcomes became obvious (Henjak 2017).

The second, and for this chapter even more important issue which shapes the conditions for policy-making in Croatia is the nature of Croatian political parties, or to be more precise, of the party that governed Croatia for 21 out 
of 29 years since the country's independence. HDZ (Croatian Democratic Union) was formed in 1990s as a party with a clear objective of achieving independence from Yugoslavia in the setting where everything was pointing to a high likelihood of Yugoslav crisis ending in an armed conflict. This resulted in the party which established a strong hierarchical organization, with decision-making centralized at the top and with a wide network of territorial organizations covering every municipality and possibly every settlement (Čular 2005; Nikić Čakar and Čular 2017). After strong party organization was established, it needed to be maintained and the only way to do it was to use government patronage at the national and local level to employ party activists and members in the public sector (Čular 2001; Henjak, Zakošek, and Čular 2013). This created sort of a reinforcing cycle for HDZ, in which the state was used to support strong party organization through patronage. Strong party organization was in turn used to support the electoral base and deliver electoral support. State resources were also used to design and deliver public policies designed to mobilize voters on symbolic issues and support partisan organization.

These two features of the policy-making context in many policies incentivised political interference in public service delivery. As demonstrated in the recent study of the reform of Croatian social services, the political executive was even stimulated to use the reform process as a route to turn collaborative service provision into opportunities for a biased distribution of public funding and for the employment of local party members as service providers. This was shown in the case of the reform of home care for older citizens (Kekez 2018a). While looking at policy-specific conditions that shaped such reform outcomes, the study revealed that the collaboration-based reform of home care services was induced during the 2000s with the objective to diminish the dominance of institution-based solutions in elderly care policy. The politicization of the reform process and outcomes, on the other hand, was enabled by the lack of well-established rules for home care provision and the absence of organizations that would represent the interest of home care beneficiaries, which served as bulwarks against political capture in other services undergoing reform (Kekez 2018a).

To find out the pathway or the mechanism through which the described capture of service reform occurred, the case of Croatian home care for older persons was further studied with the focus on the metagoverning activities executive politicians undertook in the process through which reformist ideas turned into service delivery practice. In the process-tracing analysis of evidence gathered from interviews with policy actors, official documents and statistical data, the activities of political metagovernance (see Table 12.1) were found to be present but merged with new elements that served patronage purposes. Analysis also revealed that two parts of the metagovernance process related 
to activities on the individual scale were merged in the home care reform. Moreover, in each part of the process political leaders engaged not only in activities corresponding to the notion of political metagovernance but were at the same time conducting activities through which they were politicizing their metagoverning role. The two-sided, politicized version of the metagovernance process within the Croatian home care services is shown in Figure 12.1.

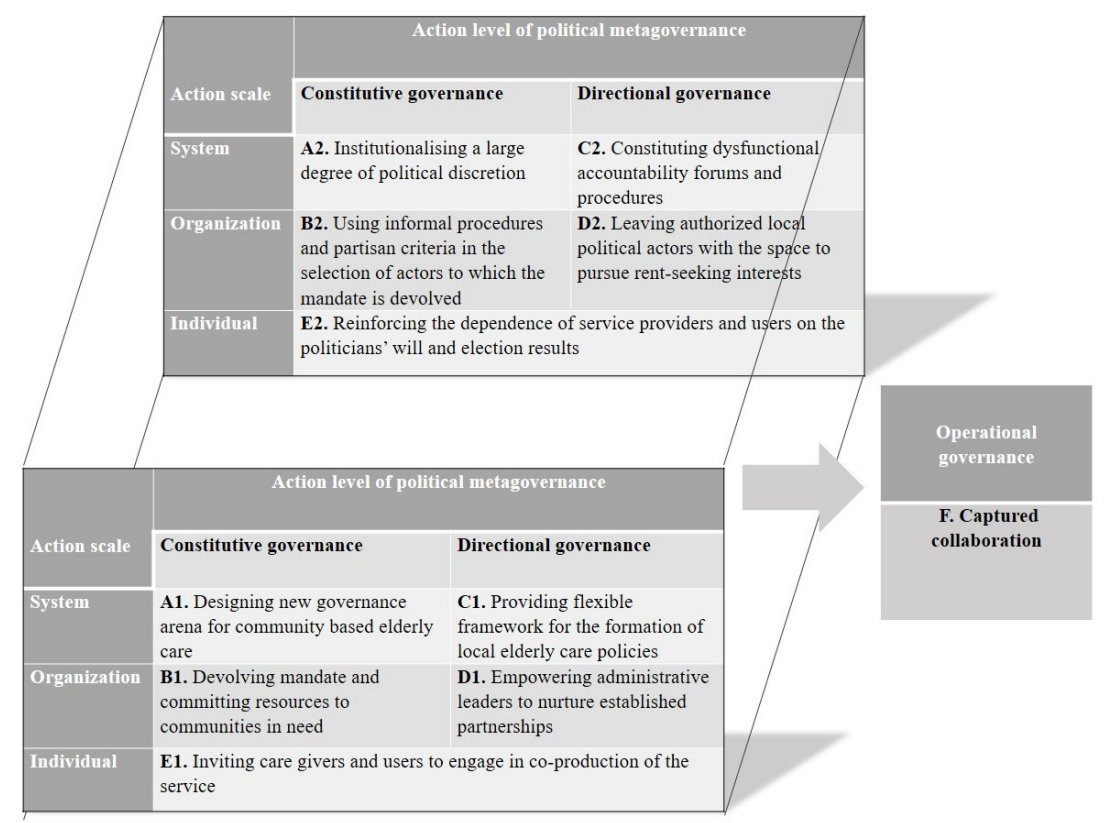

Figure 12.1 Politicized metagovernance of home care in Croatia: two sides of one coin

As highlighted in Figure 12.1 by box A1, the reform of the home care services was launched as a top-down process of structuring the new collaborative governance arena. The process was initiated in 2003 with the establishment of a new Ministry for Family, Veterans and Intergenerational Solidarity (MFVAIS) which existed during the two terms of the Croatian Democratic Union (HDZ) government and was abolished in 2011 after HDZ lost power to the Social Democratic Party-led coalition. Often referred by social policy actors as 'the Ministry of Pilot Projects,' MFVAIS launched a pilot program of home and day care services in 2004, presenting it as the new institutional setting for community-based care for older persons and as an alternative to state-based programs that already existed within the social care system. 
As the last two words of the former umbrella ministry's title suggest, the declared objectives for the constitution of this alternative governance arena were to mobilize local political leaders and community stakeholders toward a joint care for older citizens, as well as to foster a wider inclusion of older citizens, their empowerment and enhanced involvement in service delivery. To mobilize the under-utilized local resources, the provision of new home care services was detached from the de-concentrated network of bureaucratized social care institutions and organized via partnerships between state and local, usually non-profit community actors.

The introduction of these governance novelties, however, was limited only to the new home care program, while the provision of traditional home care services was left out of the political and reformist focus. By creating a new institution and the alternative mode of service provision within it, political leaders freed their own constitutive actions from the tangle of interlocking rules that were making the traditional social care system difficult to change fundamentally. In this way, as summarized in box A2, they gained a large leeway for choosing the reform package that could not only induce an interactive and user-centered organization of home care provision, but also accommodate political or even spoil-seeking interests of the ruling party.

The ability of political leaders to combine policy with spoil-seeking aims while structuring new arrangements for home care provision was further institutionalized with the two sided-design of (inter) organizational setting. On the one side, as represented in Figure 12.1 by box B1, the mandate was devolved to local actors and financial resources committed to communities in need through partnership. The MFVAIS would sign an agreement on co-funding and cooperation with the county or municipal government that would then in turn organize the provision itself or together with community organizations and homes for the elderly. The commitment to meaningful participation and collaboration of local actors was declared through documents outlining criteria for the selection of national funding recipients guiding local governments to demonstrate in their applications the willingness and ability to participate in service funding, as well as to show devotion toward partnership approach in service provision.

On the other side, the integration of the political dimension in the constitution of (inter)organizational setting was fostered via more internal procedures through which MFVAIS elected officials ensured political primacy over the selection of participating communities and actors (box B2). According to these procedures, not only were members of the committee for evaluating applications and recommending funding appointed by the Minister, but the Minister was also responsible for approving the final list of cities and municipalities that would be funded. In that final step, as indicated in interviews conducted with actors participating in the selection process, additional political criteria - such 
as partisan composition of local authorities - were informally applied on top of formal criteria, with the ranking list changed accordingly.

Such use of additional political criteria in the constitution of a new governance arena impeded this arena's integrity and representativeness. While the prevalence of politicized rules-in-use over programmatic rules-in-form challenged the capacity of administrative leaders for managing constituted partnerships, biased selection of fund recipients resulted in overrepresentation of localities governed by the ruling party. By the end of 2011, the last year in which new local units were added to the governance arena, the number of signed agreements for home care services included 59 counties and municipalities, 89 per cent with a mayor who was a member of HDZ and its coalition partners - even though HDZ and its partners were in power in 66 per cent out of 576 Croatian counties, cities and municipalities.

Within this twofold setting, as represented in Figure 12.1 by box C1, collaboration and local ownership was to be fostered through the establishment of a flexible framework for the formation of local elderly care policies. To do so, the mobilization of local actors and resources, instead of subordination and reliance on the national initiative, was to be achieved through the employment of soft management tools such as shared values, trust and the 'golden thread,' with the latter including steering through controlling budgets and personnel. Partnership agreements with supported localities were specifying desired expenses, the profile of the home care team and basic milestones regarding the number of beneficiaries the team should care for, while the monitoring of operative conduct was to be done primary based on reports localities were supposed to send to the Ministry.

In the spirit of trust, these reports did not have to be accompanied with invoices or expenditure receipts. As the provision of care was detached from the traditional social care system and its inspectors, at the beginning of each year, the Minister would appoint up to five civil servants and external experts to act as an ad hoc Committee for the Monitoring of the Program that would access local reports and recommend their approval or rejection. While basing the assessment on information provided by fund recipients, the Committee was usually acknowledging that financial and personnel conditions and basic milestones set by MVFAIS were met by all supported sites. Interviews with actors, however, indicated that constituted accountability forums and procedures proved to be dysfunctional in quite a few localities, as localities-elected officials were shrinking their reporting duty (box C2).

While MVFAIS's elected officials kept tight control over the selection of communities participating in the new home care network, after the partnership agreements were signed, national-level executive politicians would rarely directly engage in the formulation of local elderly care policies. To make sure that local solutions did not depart from the overall goals of the Program, they 
had made the Ministry's administrative leaders responsible nor only for nurturing the realization of established partnerships, but also for negotiating the policy content with local governments and other community actors (box D1). In assigning administrative leaders with negotiation tasks, however, political principals did not authorize them to endorse or reject specific solutions but decided instead to leave local political executives with freedom to pursue their own leadership style while shaping local home care programs (box D2). In view of that, while in some counties and municipalities politicians were keen on designing home care in collaboration with community organizations or homes for the older persons, in others, local governments decided to monopolize the process and use it to recruit party supporters as service providers. In localities in which the latter scenario took place, decisions on the employment of home care staff were made not only based on candidates' competences, but also on their party affiliation.

The integration of a clientelistic strategy into the selection of organizational and individual actors that would participate in the elderly care network had ambivalent effects on the users of service. On the one hand, to include a wider population in targeted communities, the inclusion of beneficiaries in service provision was left to the discretion of home care teams that were also encouraged to reach citizens that needed the service but lacked information about it. After joining the Program, as highlighted in Figure 12.1 by box E1, senior citizens were also invited to guide their caregivers in defining the intensity, regularity and elements of the care they would be receiving. In that way, citizens living in communities included in the program were offered a chance to co-produce a service and adjust it to their own needs.

On the other hand, the politicized nature of the overall service management affected the position of beneficiaries to whom, as indicated by participants in the interviews conducted, local politicians often presented home care services as direct material incentives for electoral behavior (box E2). This tendency to reinforce user dependence instead of empowerment was especially present in localities characterized by patronage practices. In that way, as summarized in Figure 12.1 by box F, instead of in the empowerment of communities and users, the reform path toward horizontal steering and collaborative delivery for Croatian elderly care resulted in the empowerment of political parties for the clientelistic capture of service provision.

\section{CONCLUSION}

In order to be successful, collaboration in public service delivery crucially depends on meaningful participation of all relevant actors in the provision of a service. Collaborative governance endows a service with democratic legitimacy and makes it more responsive to the needs of users and providers. At 
the same time it protects a service against misuse of any individual actors by putting in place checks and balances. But for an adequate balance of powers to develop, when acting in the role of metagovernors, political actors need to ensure a collaborative (re)design and delivery of public services based on democratic principles which meaningfully distribute power across multiple actors, and, perhaps more importantly, legitimize governance structures and mechanisms in the eyes of all participants irrespective of their role. This further requires that governance structure ensures representation of all groups, from providers to users and their representatives, and that it includes mechanisms holding actors accountable for their performance and making them dependent on each other.

A crucial role in this process belongs to political actors and the incentives they face. If political actors are held accountable principally on how well they govern, their motivation to first and foremost ensure democratically anchored and effective public services will be high. If, on the other hand, political actors are not held accountable for their performance in government, their orientation toward service (re)design and delivery will be affected by other considerations. Some of these considerations will make potential rewards from politicizing their metagoverning role much higher than possible electoral costs to their electoral performance. In the absence of accountability based on performance, the insufficiently institutionalized service provision and the absence of actors representing users' interest, as the case of Croatian home care reform shows, can pave the way for the politicization of collaboration-inspired (re)design of public services and its misuse for political patronage. Such development would inevitably undermine the democratic character of collaborative service delivery arrangement. It would cease to be inclusive and participative while participants, either users or providers, would be chosen with respect to biased and ascriptive criteria whose principal purpose would be allocating resources according to the political metagovernors' preferences rather than the needs of users and providers.

\section{NOTES}

1. Charismatic linkages need not be necessarily based only on the charisma of a political leader. They can also be founded on identification with parties, events, movements or conflicts which played a significant role in formation of a political identity.

2. For example, commemorative policies highly symbolic in themselves or policies where individual measures are most visible and symbolically important even if limited in scope or isolated - such as providing benefits to a limited number of war veterans or increasing child payments for families with a larger number of children, and so on. 
3. This case study is based on one of the authors' doctoral dissertation completed at the Faculty of Political Science, University of Zagreb (Kekez 2018b). 